\title{
Effects of Nanotechnology Used in Manufacturing Tennis Racquets On Some Bio-kinematic Variables.
}

\section{Sherif Fathy Saleh}

Department of Games and Sports Racquet, Faculty of Physical Education, Tanta University, Egypt.

\begin{abstract}
The current research aims to evaluate and compare the performance of five racquets used in tennis through identifying bio-kinematic variables resulting from using nanotechnology in manufacturing tennis racquets and the best Nanoenhanced racquets approved by ITF. The researcher used the experimental approach with video recording and computer-based motion analysis. The researcher purposefully chose five types of Nano-enhanced tennis racquets approved by the ITF and from different countries and manufacturers according the annual report of ITF 2014. Computer-based bio-mechanical analysis was performed using XP Digital Motion Software (final version April 2014). Results indicated that: Kinematic variables under investigation affect ball rebound velocity greatly. Values of vertical velocity SY, horizontal velocity SX and sum velocity VR vary according to using different types of Nano-enhanced racquets. Analytical and comparative studies for Nano-enhanced racquets helped showing the differences among various types of racquets.

As for ranking racquets, type two (Wilson) came first in frame flexibility and light weight in addition to inertia and more balance. Type one (Babolat) came second, type four (Prince) came third, type three (Head) came fourth and type five (Yonex) came fifth. There is a disproportionate relation as the decreased of tensile coefficient of frame flexibility causes an increase in strings cohesion and an increase in ball rebound velocity off the racquet.
\end{abstract}

Key words: Nanotechnology - Tennis Racquets - Bio-kinematic Variables - Tennis.

Introduction:

$\mathrm{M}$ odern inventions make sport more complicated. But improving performance levels and decreasing risk of injuries make sport more fun for participants and audiences. Competitive sports are deeply affected by delicate changes in sports tools and equipment that may lead to victory or defeat. Recently, the industry of sports equipment became hi-tech and more commercially profitable as it revolutionized the world of sport. This made it more profitable for private sector businesses due to the increased demand over modern sports equipment $(1: 11)$.

Mark Bartlett (2013) indicated that tennis racquets improved greatly according to performance demands of players. In designing these racquets, engineers and scientists need to know precisely what happens during ball impact to racquet in addition to physical principles of this impact. Designers strive to decrease energy waste and improve materials of manufacture. Ball/racquet impact is a unique phenomenon that becomes more complicated with the involvement of human factor. There are several unknown factors contributing in the mechanisms interpreting the effects of racquet specifications and its material characteristics on the player's abilities. Modern racquets are tougher and lighter. Nevertheless, designers seek to increase the efficiency of tennis racquets (14: 11).
During the late 20th century, companies manufacturing tennis racquets experimented on the metal mixture to design more durable and lighter frames. These experiments are called internal design aspects. Most manufacturers mixed graphite with other metals like titanium to make alloys.

Yao-Dong GU \& Jian-She Li (2007), Eric Butterman (2012), Claire Davis \& Elizabeth Swinbank (2013) and Rebecca Lake (2014) agreed that all desirable factors should be integrated in manufacturing tennis racquets. These include playing properties (power - easiness control - comfort) and mechanical qualities including mass (total mass - balance - momentum), rigidity and oscillation prevention (frame - grip). Mechanical properties are more complicated due to the use of alloys. The following are the major sectors of mechanical properties:

Engineering properties: this sector includes dimensions and shapes of all parts of the racquet. Sometimes, the design considers playing criteria like frames.

Solids properties: this sector includes mass, balance, inertia and hitting center (sweet spot). With the increase of mass, power and control increase while comfort and maneuvering decrease. Racquet balance is related to its center of gravity as the position of center of gravity indicates the type of swing. As the center of gravity is nearer to the head, power increases while comfort 
increases with center of gravity nearer to the hand $(23: 2)$ $(9: 8)(7: 115)(19: 35)$.

The researcher thinks that different manufacturers of tennis equipment work on developing materials for racquets and balls. This is clear in decreasing equipment weights and improving its durability and power compared to traditional materials like titanium, fiberglass, graphite and hyper carbon. Each manufacturer has its brand name, and patents for all components and characteristics of each racquet.

Chidambaram \& Ramakrishanan (2014) referred to the importance of carbon fibers. Carbon fibers are tubes of carbon and graphite with unique mechanical properties like rigidity, durability, strength, thermo- and electroconductivity in addition to other high profile physical properties. Nowadays, complex polymers are used with carbon (16:208).

Eric Drexler (2013) indicated that in 2007, Babolat Company worked on manufacturing tennis racquets based on research works of Cornell University. The company introduced racquets supported by Carbon Nanotubes as they manufactured racquets from carbon tubes molten with graphite. These racquets were very light and several times stronger than iron (10: 89).

Richard Osborn (2013) indicated that nanotechnology is already in use in manufacturing racquets since 2008 as Wilson Sports Ware Co. revealed its initiative of using nanotechnology through the $\mathrm{N}$. Code line for tennis racquets. These racquets contain silicon dioxide molecules to fill in the gaps among carbon fibers to enhance and support the molecular structure of the frame. This in turn enhances total stability and playability of the racquet. (20: 122).

\begin{abstract}
Abhilasha Verma (2013) indicated that in 2010 Wilson introduces BLX line of racquets where Nano fibers replace carbon fibers and basalt with maintaining silicon and basalt fibers together. This decreases vibrations and provides players with more control. Nanomaterial like Carbon Nanotubes SNPs and florin are integrated together to enhance the performance of players and equipment as well. Each Nanomaterial is responsible for an additional advantage like increased strength, durability, rigidity, anticorrosion or light weight (1:13).
\end{abstract}

Karla Okal (2011) indicated that carbon Nanotubes are the most prominent Nano materials used in NanoEnhanced Sports equipment as it can make it several times better. Nano-Enhanced sports equipment are somehow limited in the market as nanotechnology is very expensive and complicated in dealing with it. The price of one carbon nanotube ranges between 80 and 129 USD per two $\mathrm{kg}$ and this is considered very expensive (12:99).

Wilson Co. introduced the basic double technology in tennis balls. This technology is based on casting a layer of nanoparticles on the ball core. This makes the ball rebounds as twice as regular balls as this layer prevents air leak. This produces a thermoplastic air-tight casting. This helps the tennis ball to maintain its rebound for longer time in addition to using the ball longer for thorough performance $(8: 157)(5: 24)$.

Like any other invention, nanotechnology has a great effect on sports competitive abilities as it provides far greater potentials to enhance sports equipment. This makes athletes feel more safe, comfortable and flexible than ever.

Nanotechnology is used in this field for two reasons. The first is to make sports equipment stronger and the second is to make it lighter and more flexible. Some nanoparticles are hundred time stronger and six times lighter than metals used in building weather resistant buildings. Some of the Nano-enhanced equipment includes hockey sticks, baseball bats, tennis racquets and balls, golf putters and balls, bikes and archery arrows (4:13).

International Tennis Federation (ITF) (2014) is the body responsible for accrediting and allowing the use of tennis equipment in training and competitions. Rules and regulations of the ITF indicate that there are no rules for sizes or weights of tennis racquets as they are different and vary greatly. Racquet length should not exceed $73.9 \mathrm{~cm}$ while frame width should not exceed $31.7 \mathrm{~cm}$. Racquet face width should not exceed $29.3 \mathrm{~cm}$ and its length should not exceed $39.4 \mathrm{~cm}$. Racquet weight may range between $255 \mathrm{~g}$ and $340 \mathrm{~g}(11: 157)$.

Egyptian tennis players in junior and men stages use these various types of Nano-enhanced racquets just like elite players. Unfortunately, there is no scientific base to identify the best type and its effects on bio-kinematic properties of the rebound ball for Nano-enhanced racquets.

Amal Gaber (2013) indicated that biomechanics is the field concerned with studying and analyzing time. It aims to find best bio-kinematic solutions to achieve training tasks (4: 36).

B. Elliott (2009) indicates that biomechanical analyses for racquet sports (badminton - squash - table tennis - tennis) are meant to identify mechanical variables affecting performance. The most important applied field for these analyses is the technique of strokes. Recent technological advances provided us with detailed 3D kinematic and mechanical properties of racquet skills. Biomechanics 
specialists were able to examine the implied mechanisms used in racquet skills. Although there are several factors involved in the mechanical behavior of the racquet, ball surface and the environment, all these factors are outside the scope of this general view that will be limited to the applications of biomechanics to understand the technique of racquet sports and its applications for improving performance and injury prevention (6:114).

The researcher thinks that various types of Nano-enhanced racquets may affect the velocity of ball hitting. According to the researcher's knowledge, there are no previous studies that dealt with the effects of Nano-enhanced racquets on some bio-kinematic variables of the rebound ball. Therefore, the researcher is trying to identify some bio-kinematic variables of the rebound ball in tennis as this kind of data plays a major role in identifying the best Nano-enhanced racquets to be used in Egypt according to scientific diagnosis based on inquiry directed towards the bio-kinematic explanations of one of the most important problems faced in sport.

The researcher assures that there are three ways to evaluate Nano-enhanced racquets and its effects on performance. First of all there is the player's evaluation which is non-objective. Second, there is the manufacturer's evaluation which is non-objective too. Third, there is the bio-kinematic analysis of properties for the rebound ball after hitting with Nano-enhanced racquets. This type of evaluation is extremely objective. The current research is trying to identify the effects of nanotechnology on some bio-kinematic variables of the rebound ball with various approved racquets to identify the best type of Nano-enhanced racquets referring to velocity.

Aims:

The current research aims to evaluate and compare the performance of five racquets used in tennis through:

- Identifying bio-kinematic variables resulting from using nanotechnology in manufacturing tennis racquets

- Identifying the best Nano-enhanced racquets approved by ITF

\section{Hypotheses:}

The current research is trying to answer the following questions:

- What are the bio-kinematic variables resulting from using nanotechnology in manufacturing tennis racquets?
- What are the best Nano-enhanced racquets approved by ITF?

\section{Terminology:}

- Nanotechnology: It is the study of basic concepts of molecules and compound not exceeding 100 nanometer. A Nano is 80.000 smaller than a human hair fiber.

- Carbon Nanotube: It is a cylindrical multi-walls Nanotube. The ratio between the length of a Carbon Nanotube and its diameter is $1: 132.000 .000(1: 11)$.

\section{$\underline{\text { Review of literature: }}$}

Toth-Tascau Mirela et al (2010) performed a study titled by "Design aspects of a tennis racket". The purpose of the study was to design a simulation model for the edges of tennis racquet using linear equations. The researchers used the experimental approach on a sample of one racquet using 3D modeling and computer motion analysis. The researchers concluded a model for the racquet according to numerical analysis for studying the mechanical properties of the racquet, especially the mutual effects of the tennis ball and a series of various skills (22).

Chidambaram \& Ramakrishanan (2014) performed a study titled by "Impact, String Tension and Vibration Analysis of Nancomposite Based Tennis Racket Frame". The purpose of the study was to design a 3D model for the tennis racquet frame and 3D model for the tennis ball. The researchers used the experimental approach on a sample of one racquet and one ball using 3D modeling and computer motion analysis. The researchers designed a 3D model for the tennis racquet frame and 3D model for the tennis ball with frequencies of 171 to $191 \mathrm{~Hz}$. The best frequency for the sweet spot was $162 \mathrm{~Hz}$ (16).

These two studies did not evaluate or compare the five types of Nano-enhanced tennis racquets due to the limitations of approach, samples, statistical treatments and methods of motion analysis.

\section{Methods:}

\section{Approach:}

The researcher used the experimental approach with video recording and computer-based motion analysis. 


\section{Sample:}

The researcher purposefully chose five types of Nanoenhanced tennis racquets approved by the ITF and from

Table (1):

Types of Nano-enhanced tennis racquets under investigation

\begin{tabular}{|c|c|c|c|c|c|}
\hline S & Kind (brand) & Height & width & Frame distance & Weight \\
\hline 1 & Babolat & 68.5 & 25 & 975 & 325 \\
\hline 2 & Wilson & 65.8 & 29 & 945 & 270 \\
\hline 3 & Head & 66.4 & 27 & 952 & 290 \\
\hline 4 & Prince & 68.7 & 26 & 884 & 256 \\
\hline 5 & Yonex & 70.5 & 29 & 644 & 310 \\
\hline
\end{tabular}

The researcher chose the sample according to the following criteria:

1. All racquets are approved by the ITF and Association of Professional Tennis Players (Annex A)

2. Users of these types are ranked from (1) to (50) in the list of Association of Professional Tennis Players (2:6)

3. All racquets are manufactured using nanotechnology and comply with criteria of ITF concerning physical and chemical structures

The purpose of this research is to quantify the biokinematic properties of Nano-enhanced tennis racquets. The researcher reduced the number of recorded attempts from (80) to only (10) eliminating incorrect attempts.

\section{Data collection tools:}

To collect data, the researcher used the following tools:

1. A tennis robot (Prince 2013) (21) (Annex B)

2. One video camera (National M3000 - 25hz/sec)

3. One short tripod

4. One video cassette

5. Markers

6. Measuring tape

7. Tennis court

8. High-speed flasher

9. Tennis balls (Prince - yellow) used for the first time different countries and manufacturers according the annual report of ITF 2014.
10. Five Nano-enhanced racquets (Babolat - Wilson - Head - Prince - Yonex) with Ultra Super Light Strings

11. Babolat RDC device (2013) to identify the standards and mechanical properties of the tennis racquets. (3:3) (Annex C)

For computer-based motion analysis, the researcher used the following tools:

1. Video recorder

2. Video blaster

3. Computer

4. Printer

5. Motion analysis software

6. Monitor

Computer-based biomechanical analysis was performed using XP Digital Motion Software (final version April 2014) as it is suitable for motion analysis from various levels according to the approach and nature of analysis according to the following steps:

1. Video Capture to transfer the film from video mode to digital mode as the software automatically calculates the camera speed

2. Dividing the film into parts and each part includes only one attempt to only one racquet. Attempts are automatically numbered and each attempt is divided into four stages:

- Stage one (pre-contact): from the ball coming out of the tennis robot until just before impact with racquet

- $\quad$ Stage two (contact): the moment of ball/racquet impact 
- $\quad$ Stage three (post-contact): after the moment of ball/racquet impact

- $\quad$ Stage four (rebound effect): from the moment of ball touching the racquet until after rebound to floor

3. Motion analysis procedures:

- Identifying motion axes with the center of hitting

- $\quad$ Identifying the scale through markers

- Choosing stages and frames for analysis and figure (1) shows some main frames for analysis. Racquet center of gravity was used for trajectory according to previously chosen indications

4. The software automatically calculates momentary change functions for horizontal $(\mathrm{x})$ and vertical (y) axes in addition to calculating main functions of distances (S), velocities (V) and acceleration (a) for each stage under analysis.

5. Saving and printing results

\section{Pilot study:}

The researcher performed the pilot study on 25-10-2014 in BSS Emirates Academy Tennis (UAE) using the same tools of the main study for the following reasons:

1. Preparing the place for shooting and choosing the right time

2. Identifying the suitable distance for cameras on both sides of the net $(135 \mathrm{~cm}$ high from floor $840 \mathrm{~cm}$ away from the right side of ball movement)

3. Identifying the field of motion inside camera range

4. Identifying places of fixing scales

5. Identifying the suitable height of cameras and the right side for shooting

6. Assuring the validity of balls and nets and its fulfillment of legal requirements

7. Assuring color contrast (yellow for balls - red for floor - black for net)

8. Assuring the way of fixing racquet correctly with the right angle ( $90^{\circ}$ on floor) to the net pole
9. Assuring the functionality of the tennis robot and identifying its speed (50 balls/min) and the camera speed as well

10. Identifying the right velocity for balls getting out of the tennis robot $(650 \mathrm{~m} / \mathrm{sec})$.

\section{Main Study:}

The researcher performed the main study on 9-11-2014 in BSS Emirates Academy Tennis (UAE)

\section{Video Recording Protocol: (Annex D)}

The place was set for video recording as follows:

- $\quad$ One camera was set on $135 \mathrm{~cm}$ above the ground and $840 \mathrm{~cm}$ to the left side of the ball

- The racquet was fixed $120 \mathrm{~cm}$ above the ground on one of the net poles

- Distance between tennis robot and racquet was $430 \mathrm{~cm}(1,1,150,80)$ and marked by yellow marker. Video recording followed the protocol of Kannan \& Ramakrishnan (2012) (17:238)

\section{Tennis Robot Functioning:}

This device is used to put the ball at any place of the court accurately with various velocities and with/without spins. The researcher used 20balls/min (3 seconds duration) and throwing the ball directly to the racquet.

- Variables under investigation were calculated as follows: horizontal and vertical distances $\left(\mathrm{S}_{\mathrm{X}}-\right.$ $\left.S_{Y}\right)$ - horizontal, vertical and sum velocities $\left(V_{X}\right.$ - $\mathrm{V}_{\mathrm{Y}}-\mathrm{V}_{\mathrm{R}}$ ) - horizontal, vertical and sum acceleration $\left(a_{X}-a_{Y}-a_{R}\right)$.

- $\quad$ Each attempt was divided into (4) stages

Testing standards and qualities of Nano-enhanced tennis racquets:

- $\quad$ Purpose: identifying the standards and qualities of Nano-enhanced tennis racquets

- Tools: Babolat RDC device (2013) to quantify mechanical properties including weight, strings' tightness, frame flexibility, inertia and balance.

- Procedures: the racquet is fixed to the testing device as its axis is the loading axis .(3:3) 
Figure (1):

Some Main Frames of the Bio-Kinematic Analysis
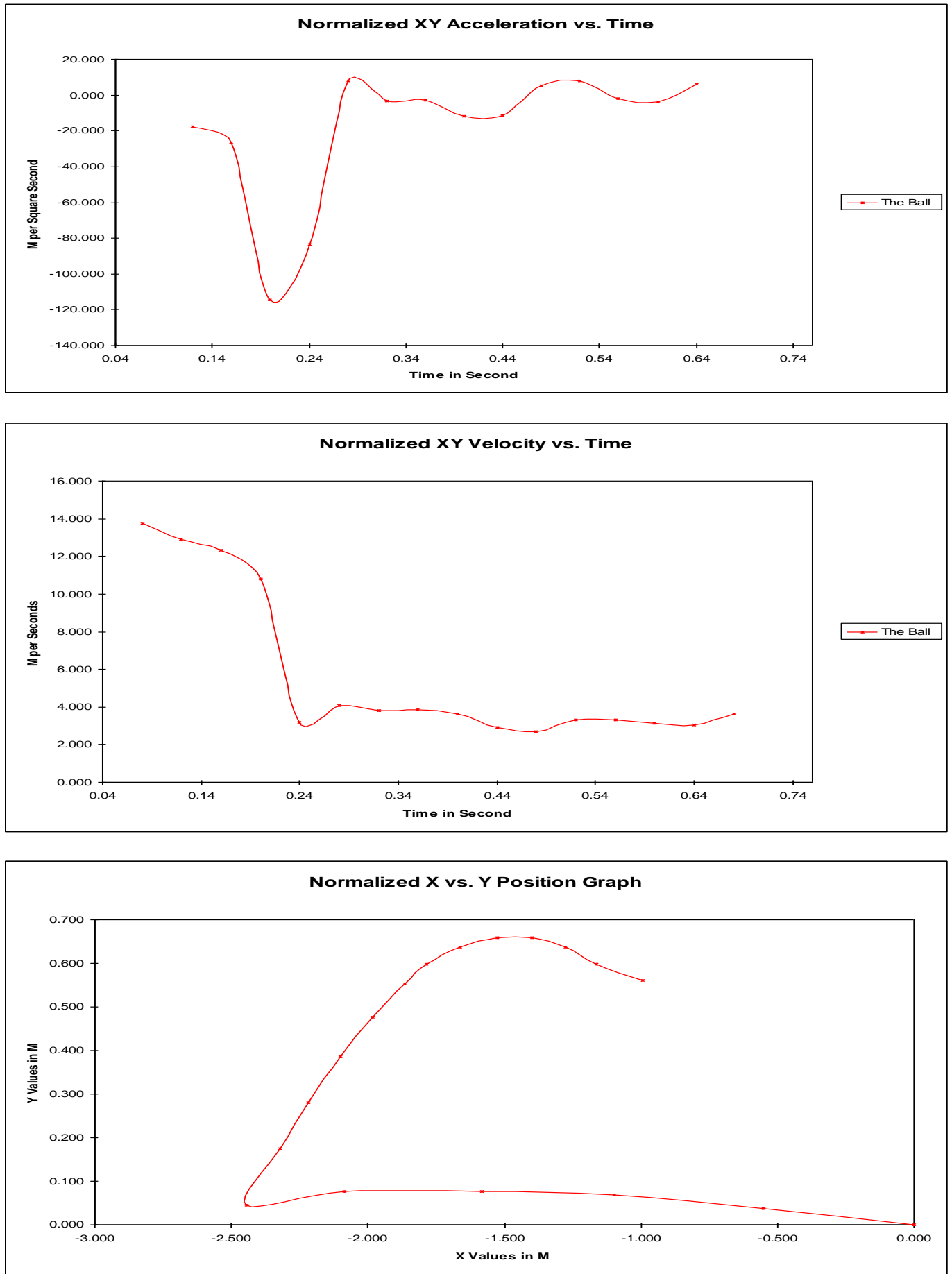

\section{Statistical treatment:}

The researcher used variance analysis (one-way ANOVA) with LSD to identify velocities, accelerations, distances and final velocity during stages three (post-contact) and four (rebound effect). 


\section{Results:}

A) Post-Contact Stage:

Table (2):

means and SD for horizontal (X) and vertical (Y) coordinates of Distances (S) of the rebound ball from every type of Nano-enhanced tennis racquets during the third stage (post-contact)

\begin{tabular}{|c|c|c|c|c|c|}
\hline \multirow{2}{*}{$S$} & \multirow{2}{*}{$\begin{array}{c}\text { Kind } \\
\text { (brand) }\end{array}$} & Means & SD Cm & Means & SD \\
\cline { 2 - 5 } & Babolat & 1.8625 & 0.03568 & 0.8660 & 0.0774 \\
\hline 1 & Wilson & 1.7800 & 0.23289 & 0.3335 & 0.4740 \\
\hline 2 & Head & 1.6065 & 0.43149 & 0.4715 & 0.0878 \\
\hline 3 & Prince & 1.7545 & 0.01936 & 0.3365 & 0.1013 \\
\hline 4 & Yonex & 1.3735 & 0.27780 & 0.2360 & 0.1789 \\
\hline 5 & Total & 1.6754 & 0.19940 & 0.5087 & 0.1839 \\
\hline
\end{tabular}

Table (2) indicates that SX values ranged between (1.3735) and (1.8625). while SY values ranged between (0.2360) and (0.8660).

Table (3):

means and SD for horizontal (X) and vertical (Y) coordinates of Velocities (V) and sum velocity (R) of the rebound ball from every type of Nano-enhanced tennis racquets during the third stage (post-contact)

\begin{tabular}{|c|c|c|c|c|c|c|c|}
\hline \multirow{2}{*}{$S$} & \multirow{2}{*}{$\begin{array}{c}\text { Kind } \\
\text { (brand) }\end{array}$} & \multicolumn{2}{|c|}{ Vx cm/sec } & \multicolumn{2}{c|}{ Vy cm/sec } & \multicolumn{2}{c|}{ VR cm/sec } \\
\cline { 3 - 8 } & Means & SD & Means & SD & Means & SD \\
\hline 1 & Babolat & 7.7405 & 1.8601 & 7.5110 & 0.5081 & 8.053 & 0.423 \\
\hline 2 & Wilson & 8.0550 & 0.9556 & 6.4885 & 0.1827 & 7.910 & 0.664 \\
\hline 3 & Head & 4.1245 & 0.6142 & 5.1805 & 3.3618 & 4.057 & 0.055 \\
\hline 4 & Prince & 4.2715 & 0.9768 & 3.9715 & 1.3544 & 4.118 & 0.850 \\
\hline 5 & Yonex & 3.2965 & 1.5396 & 7.2730 & 1.7293 & 2.661 & 0.649 \\
\hline & Total & 5.4876 & 1.18926 & 6.0849 & 1.4272 & 5.359 & 0.534 \\
\hline
\end{tabular}

Table (3) indicates that VX values ranged between (3.2965) and (8.005) $\mathrm{cm} / \mathrm{sec}$ while VY ranged between (3.9715) and (7.511) $\mathrm{cm} / \mathrm{sec}$. VR values ranged between (2.6614) and (8.053).

Table (4):

means and SD for horizontal (X) and vertical (Y) coordinates of Accelerations (a) and sum acceleration (R) of the rebound ball from every type of Nano-enhanced tennis racquets during the third stage (post-contact)

\begin{tabular}{|c|c|c|c|c|c|c|c|}
\hline \multirow{2}{*}{$S$} & \multirow{2}{*}{$\begin{array}{c}\text { Kind } \\
\text { (brand) }\end{array}$} & \multicolumn{2}{|c|}{$\mathrm{ax} \mathrm{cm} / \mathrm{sec} 2$} & \multicolumn{2}{|c|}{ ay cm/sec2 } & \multicolumn{2}{c|}{ aR cm/sec2 } \\
\cline { 3 - 8 } & Beans & SD & Means & SD & Means & SD \\
\hline 1 & Babolat & 30.208 & 1.6834 & 12.655 & 1.0527 & 39.606 & 9.4008 \\
\hline 2 & Wilson & 22.412 & 1.2230 & 13.101 & 0.6354 & 38.623 & 1.0936 \\
\hline 3 & Head & 15.172 & 6.9483 & 11.285 & 2.8750 & 14.548 & 1.3452 \\
\hline 4 & Prince & 15.807 & 1.5484 & 12.786 & 0.8673 & 16.974 & 0.1673 \\
\hline 5 & Yonex & 13.931 & 0.5196 & 11.520 & 0.1045 & 13.104 & 1.7898 \\
\hline & Total & 19.506 & 2.38454 & 12.269 & 1.1069 & 24.571 & 2.7534 \\
\hline
\end{tabular}

Table (4) indicates that aX values ranged between (13.931) and (30.208) $\mathrm{cm} / \mathrm{sec} 2$ while aY values ranged between $(11.285)$ and $(13.101) \mathrm{cm} / \mathrm{sec} 2$. aR values ranged between $(13.104)$ and $(39.606) \mathrm{cm} / \mathrm{sec} 2$. 


\section{B) Rebound Effect Stage:}

Table (5):

means and SD for horizontal (X) and vertical (Y) coordinates of Distances (S) of the rebound ball from every type of Nano-enhanced tennis racquets during the third stage (rebound effect)

\begin{tabular}{|c|c|c|c|c|c|}
\hline \multirow{2}{*}{$S$} & \multirow{2}{*}{$\begin{array}{c}\text { Kind } \\
\text { (brand) }\end{array}$} & Means & SD Cm & Means & SD \\
\cline { 3 - 6 } & Babolat & 0.4400 & 0.0335 & 0.6300 & 0.1325 \\
\hline 1 & Wilson & 0.4700 & 0.1763 & 0.3305 & 0.3792 \\
\hline 2 & Head & 0.1555 & 0.5531 & 0.2270 & 0.0828 \\
\hline 3 & Prince & 0.3360 & 0.0724 & 0.2140 & 0.1063 \\
\hline 4 & Yonex & 0.2390 & 0.2259 & 0.3285 & 0.2464 \\
\hline 5 & Total & 0.3281 & 0.2122 & 0.3460 & 0.1894 \\
\hline
\end{tabular}

Table (5) indicates that SX values ranged between (0.1555) and (0.4700). While SY values ranged between (0.2140) and (0.6300).

Table (6):

means and SD for horizontal (X) and vertical (Y) coordinates of Velocities (V) and sum velocity (R) of the rebound ball from every type of Nano-enhanced tennis racquets during the third stage (rebound effect)

\begin{tabular}{|c|c|c|c|c|c|c|c|}
\hline \multirow{2}{*}{$S$} & \multirow{2}{*}{$\begin{array}{c}\text { Kind } \\
\text { (brand) }\end{array}$} & \multicolumn{2}{|c|}{ Vx cm/sec } & \multicolumn{2}{c|}{ Vy cm/sec } & \multicolumn{2}{c|}{ VR cm/sec } \\
\cline { 3 - 8 } & Means & SD & Means & SD & Means & SD \\
\hline 1 & Babolat & 19.991 & 2.1259 & 19.306 & 1.4115 & 55.558 & 1.4457 \\
\hline 2 & Wilson & 22.514 & 1.1834 & 20.657 & 0.4942 & 65.090 & 3.6695 \\
\hline 3 & Head & 15.428 & 1.0135 & 18.571 & 2.7313 & 56.603 & 6.4476 \\
\hline 4 & Prince & 16.220 & 1.6825 & 20.288 & 1.7706 & 60.955 & 9.0895 \\
\hline 5 & Yonex & 15.581 & 1.9938 & 17.934 & 0.2937 & 67.933 & 4.8915 \\
\hline & Total & 17.946 & 1.5998 & 19.351 & 1.3402 & 61.227 & 5.1087 \\
\hline
\end{tabular}

Table (6) indicates that VX values ranged between (15.425) and (22.514) cm/sec while VY ranged between (17.934) and (20.657) $\mathrm{cm} / \mathrm{sec}$. VR values ranged between (55.558) and (67.933).

Table (7):

means and SD for horizontal (X) and vertical (Y) coordinates of Accelerations (a) and sum acceleration (R) of the rebound ball from every type of Nano-enhanced tennis racquets during the third stage (rebound effect)

\begin{tabular}{|c|c|c|c|c|c|c|c|}
\hline \multirow{2}{*}{$S$} & \multirow{2}{*}{$\begin{array}{c}\text { Kind } \\
\text { (brand) }\end{array}$} & \multicolumn{2}{|c|}{$\mathrm{ax} \mathrm{cm} / \mathrm{sec} 2$} & \multicolumn{2}{|c|}{ ay cm/sec2 } & \multicolumn{2}{c|}{ aR cm/sec2 } \\
\cline { 3 - 8 } & Means & SD & Means & SD & Means & SD \\
\hline 1 & Babolat & 5.756 & 0.0783 & 107.04 & 15.648 & 4.115 & 0.2649 \\
\hline 2 & Wilson & 5.004 & 0.7033 & 98.814 & 0.9126 & 4.088 & 0.8998 \\
\hline 3 & Head & 3.668 & 3.6157 & 80.884 & 2.2185 & 7.994 & 0.5363 \\
\hline 4 & Prince & 2.620 & 1.9308 & 79.219 & 2.4477 & 7.571 & 0.8228 \\
\hline 5 & Yonex & 6.008 & 1.6043 & 78.027 & 6.0923 & 9.373 & 1.1510 \\
\hline & Total & 4.611 & 1.8564 & 88.796 & 5.46382 & 6.627 & 0.7349 \\
\hline
\end{tabular}

Table (7) indicates that aX values ranged between $(2.6200)$ and $(6.0085) \mathrm{cm} / \mathrm{sec} 2$ while aY values ranged between (78.027) and $(107.04) \mathrm{cm} / \mathrm{sec} 2$. aR values ranged between $(4.0885)$ and $(9.373) \mathrm{cm} / \mathrm{sec} 2$. 
Table (8):

Variance analysis of the rebound ball from every type of Nano-enhanced tennis racquets during the third stage (post-contact)

\begin{tabular}{|c|c|c|c|c|c|c|}
\hline S & Variables & Source of variation & Sum of Squares & df & Mean Square & $\mathrm{F}$ \\
\hline \multirow{3}{*}{1} & \multirow{3}{*}{$\mathrm{Sx} \mathrm{cm}$} & Between Groups & 0.231 & 4 & 0.046 & \multirow{3}{*}{1.207} \\
\hline & & Within Groups & 0.191 & 5 & 0.032 & \\
\hline & & Total & 0.422 & 9 & & \\
\hline \multirow{3}{*}{2} & \multirow{3}{*}{ Sy cm } & Between Groups & 0.262 & 4 & 0.610 & \multirow{3}{*}{1.134} \\
\hline & & Within Groups & 0.241 & 5 & 0.043 & \\
\hline & & Total & 0.503 & 9 & & \\
\hline \multirow{3}{*}{3} & \multirow{3}{*}{$\mathrm{Vx} \mathrm{cm} / \mathrm{sec}$} & Between Groups & 48.341 & 4 & 6.231 & \multirow{3}{*}{$6.045 *$} \\
\hline & & Within Groups & 6.686 & 5 & 1.013 & \\
\hline & & Total & 55.027 & 9 & & \\
\hline \multirow{3}{*}{4} & \multirow{3}{*}{$\mathrm{Vy} \mathrm{cm} / \mathrm{sec}$} & Between Groups & 14.768 & 4 & 2.098 & \multirow{3}{*}{1.190} \\
\hline & & Within Groups & 13.695 & 5 & 2.318 & \\
\hline & & Total & 28.463 & 9 & & \\
\hline \multirow{3}{*}{5} & \multirow{3}{*}{$\mathrm{VR} \mathrm{cm} / \mathrm{sec}$} & Between Groups & 43.769 & 4 & 7.095 & \multirow{3}{*}{$14.209 *$} \\
\hline & & Within Groups & 3.320 & 5 & 0.501 & \\
\hline & & Total & 47.089 & 9 & & \\
\hline \multirow{3}{*}{6} & \multirow{3}{*}{$\mathrm{ax} \mathrm{cm} / \mathrm{sec} 2$} & Between Groups & 452.986 & 4 & 77.225 & \multirow{3}{*}{$5.132 * *$} \\
\hline & & Within Groups & 142.529 & 5 & 19.366 & \\
\hline & & Total & 595.515 & 9 & & \\
\hline \multirow{3}{*}{7} & \multirow{3}{*}{ ay $\mathrm{cm} / \mathrm{sec} 2$} & Between Groups & 49.269 & 4 & 8.635 & \multirow{3}{*}{3.317} \\
\hline & & Within Groups & 8.181 & 5 & 1.528 & \\
\hline & & Total & 57.45 & 9 & & \\
\hline \multirow{3}{*}{8} & \multirow{3}{*}{$\mathrm{aR} \mathrm{cm} / \mathrm{sec} 2$} & Between Groups & 1682.75 & 4 & 251.420 & \multirow{3}{*}{$18.663 *$} \\
\hline & & Within Groups & 59.325 & 5 & 11.403 & \\
\hline & & Total & 1742.075 & 9 & & \\
\hline
\end{tabular}

\section{** Significant on 0.05}

Table (8) indicates statistically significant differences for rebound ball among all types of Nano-enhanced racquets during the third stage (post-contact) on all variables except for SX, SY, VY and aY. This led the researcher to perform LSD test to identify these differences. 
Table (9):

LSD comparison for horizontal (X) and vertical (Y) coordinates of Distances (S) of the rebound ball from every type of Nano-enhanced tennis racquets during the third stage (post-contact)

\begin{tabular}{|c|c|c|c|c|}
\hline $\mathrm{s}$ & Comparison & Racquet Type & $\mathrm{Sx} \quad \mathrm{Cm}$ & $\mathrm{Cm} \mathrm{Sy}$ \\
\hline \multirow{4}{*}{1} & \multirow{4}{*}{ Babolat } & 2 & 0.1125 & 0.2425 \\
\hline & & 3 & 0.1860 & 0.3045 \\
\hline & & 4 & 0.0180 & 0.4165 \\
\hline & & 5 & 0.3790 & 0.5000 \\
\hline \multirow{4}{*}{2} & \multirow{4}{*}{ Wilson } & 1 & 0.1125 & 0.2425 \\
\hline & & 3 & 0.3350 & 0.0020 \\
\hline & & 4 & 0.0545 & 0.1170 \\
\hline & & 5 & 0.2265 & 0.1975 \\
\hline \multirow{4}{*}{3} & \multirow{4}{*}{ Head } & 1 & 0.1860 & 0.3045 \\
\hline & & 2 & 0.3350 & 0.0020 \\
\hline & & 4 & 0.1280 & 0.0550 \\
\hline & & 5 & 0.1530 & 0.1355 \\
\hline \multirow{4}{*}{4} & \multirow{4}{*}{ Prince } & 1 & 0.0180 & 0.4165 \\
\hline & & 2 & 0.0545 & 0.1170 \\
\hline & & 3 & 0.1280 & 0.0550 \\
\hline & & 5 & 0.3210 & 0.0205 \\
\hline \multirow{4}{*}{5} & \multirow{4}{*}{ Yonex } & 1 & 0.3790 & 0.5000 \\
\hline & & 2 & 0.2265 & 0.1975 \\
\hline & & 3 & .15300 & 0.1355 \\
\hline & & 4 & 0.3210 & 0.0205 \\
\hline
\end{tabular}

\section{** Significant on 0.05}

Table (9) indicates no statistically significant differences among the five types of racquets on SX or SY.

Table (10):

LSD comparison for horizontal (X) and vertical (Y) coordinates of Velocities (V) and sum velocity (R) of the rebound ball from every type of Nano-enhanced tennis racquets during the third stage (post-contact)

\begin{tabular}{|c|c|c|c|c|c|}
\hline $\mathrm{s}$ & Comparison & Racquet Type & $\begin{array}{c}\mathrm{Vx} \\
\mathrm{cm} / \mathrm{sec}\end{array}$ & $\begin{array}{c}\mathrm{Vy} \\
\mathrm{cm} / \mathrm{sec}\end{array}$ & $\begin{array}{c}\mathrm{VR} \\
\mathrm{cm} / \mathrm{sec}\end{array}$ \\
\hline \multirow{4}{*}{1} & \multirow{4}{*}{ Babolat } & 2 & 0.1545 & 1.03300 & 0.1330 \\
\hline & & 3 & $* 3.546$ & 2.2410 & $* 3.8855$ \\
\hline & & 4 & $* * 3.379$ & 3.4300 & *3.8045 \\
\hline & & 5 & $* 4.3340$ & 0.10850 & $* 5.2415$ \\
\hline \multirow{4}{*}{2} & \multirow{4}{*}{ Wilson } & 1 & 0.1545 & 1.03300 & 0.1330 \\
\hline & & 3 & $* 3.7405$ & 1.14800 & $* 3.6725$ \\
\hline & & 4 & $* 3.5735$ & 2.33700 & $* 3.5915$ \\
\hline & & 5 & $* 4.5285$ & 0.86450 & $* 5.0285$ \\
\hline \multirow{3}{*}{3} & \multirow{3}{*}{ Head } & 1 & $* 3.5460$ & 2.24100 & $* 3.8855$ \\
\hline & & 2 & $* 3.7405$ & 1.14800 & $* 3.6725$ \\
\hline & & 4 & 0.12700 & 1.12900 & 0.0010 \\
\hline
\end{tabular}




\begin{tabular}{|c|c|c|c|c|c|}
\hline $\mathrm{s}$ & Comparison & Racquet Type & $\begin{array}{c}\mathrm{Vx} \\
\mathrm{cm} / \mathrm{sec}\end{array}$ & $\begin{array}{c}\mathrm{Vy} \\
\mathrm{cm} / \mathrm{sec}\end{array}$ & $\begin{array}{c}\text { VR } \\
\mathrm{cm} / \mathrm{sec}\end{array}$ \\
\hline & & 5 & 0.74800 & 2.07250 & 1.2760 \\
\hline \multirow{4}{*}{4} & \multirow{4}{*}{ Prince } & 1 & *3.3790 & 3.43000 & $* 3.8045$ \\
\hline & & 2 & 3.57350 & 2.33700 & $* 3.5915$ \\
\hline & & 3 & 0.12700 & 1.12900 & 0.0010 \\
\hline & & 5 & 0.91500 & 3.26150 & 1.3570 \\
\hline \multirow{4}{*}{5} & \multirow{4}{*}{ Yonex } & 1 & $* 4.3340$ & 0.10850 & $* 5.2415$ \\
\hline & & 2 & $* 4.52850$ & 0.86450 & $* 5.0285$ \\
\hline & & 3 & 0.74800 & 2.07250 & 1.2760 \\
\hline & & 4 & 0.91500 & 3.26150 & 1.3570 \\
\hline
\end{tabular}

\section{** Significant on 0.05}

Table (10) indicates statistically significant differences among all types with type one and type two but not with types three, four and five. Comparing types one and two, there are statistically significant differences on VX in favor of type two. There are not statistically significant differences among the five types on VY. There are statistically significant differences among all types and types one and two but not three and four. Comparing types one and two, there are statistically significant differences on VR in favor of type one.

Table (11):

LSD comparison for horizontal $(\mathrm{X})$ and vertical (Y) coordinates of Accelerations (a) and sum acceleration (R) of the rebound ball from every type of Nano-enhanced tennis racquets during the third stage (post-contact)

\begin{tabular}{|c|c|c|c|c|c|}
\hline s & Comparison & Racquet Type & ax cm/sec 2 & ay $\mathrm{cm} / \mathrm{sec} 2$ & $\mathrm{aR} \mathrm{cm} / \mathrm{sec} 2$ \\
\hline \multirow{4}{*}{1} & \multirow{4}{*}{ Babolat } & 2 & 7.2665 & 0.297 & 2.9530 \\
\hline & & 3 & *14.406 & 1.259 & $* 24.928$ \\
\hline & & 4 & $* 13.751$ & 0.098 & $* 22.482$ \\
\hline & & 5 & $* 15.607$ & 0.984 & $* 26.332$ \\
\hline \multirow{4}{*}{2} & \multirow{4}{*}{ Wilson } & 1 & 7.2665 & 0.297 & 2.9530 \\
\hline & & 3 & 6.5395 & 1.636 & $* 21.872$ \\
\hline & & 4 & 5.8845 & 0.118 & $* 19.429$ \\
\hline & & 5 & 7.7405 & 1.361 & $* 23.279$ \\
\hline \multirow{4}{*}{3} & \multirow{4}{*}{ Head } & 1 & $* 14.406$ & 1.256 & $* 24.928$ \\
\hline & & 2 & 6.5395 & 1.636 & $* 21.875$ \\
\hline & & 4 & 0.0550 & 1.437 & 2.3455 \\
\hline & & 5 & 0.6010 & 0.194 & 1.3045 \\
\hline \multirow{4}{*}{4} & \multirow{4}{*}{ Prince } & 1 & $* 13.751$ & 0.098 & $* 22.482$ \\
\hline & & 2 & 5.8845 & 0.118 & *19.429 \\
\hline & & 3 & .05500 & 1.4375 & 2.3455 \\
\hline & & 5 & 1.2560 & 1.163 & 3.7500 \\
\hline \multirow{4}{*}{5} & \multirow{4}{*}{ Yonex } & 1 & $* 15.607$ & 0.985 & $* 26.332$ \\
\hline & & 2 & 7.7405 & 1.361 & $* 23.279$ \\
\hline & & 3 & 0.6010 & 0.194 & 1.3045 \\
\hline & & 4 & 1.2560 & 1.163 & 3.7500 \\
\hline
\end{tabular}

\footnotetext{
** Significant on 0.05
} 
Table (11) indicates statistically significant difference among all types and type one in favor of type two. Comparing type two with other variables did not reveal any statistically significant difference on aX. There are no statistically significant differences among the five types on aY. There are statistically significant differences between type one and the other types but not type two. There are statistically significant differences between type two and the other types but not type one on aR in favor of type one. Comparing types three and four with other variables, statistically significant differences appear only between types one and two on aR in favor of type one.

Table (12):

Variance analysis of the rebound ball from every type of Nano-enhanced tennis racquets during the third stage (rebound effect)

\begin{tabular}{|c|c|c|c|c|c|c|}
\hline S & Variables & Source of variation & Sum of Squares & df & Mean Square & $\mathrm{F}$ \\
\hline \multirow{3}{*}{1} & \multirow{3}{*}{$\mathrm{Sx} \mathrm{cm}$} & Between Groups & 0.654 & 4 & 0.116 & \multirow{3}{*}{2.243} \\
\hline & & Within Groups & 0.270 & 5 & 0.049 & \\
\hline & & Total & 0.924 & 9 & & \\
\hline \multirow{3}{*}{2} & \multirow{3}{*}{ Sy cm } & Between Groups & 0.434 & 4 & 0.82 & \multirow{3}{*}{1.510} \\
\hline & & Within Groups & 0.281 & 5 & 0.046 & \\
\hline & & Total & 0.715 & 9 & & \\
\hline \multirow{3}{*}{3} & \multirow{3}{*}{$\mathrm{Vx} \mathrm{cm} / \mathrm{sec}$} & Between Groups & 95.432 & 4 & 15.621 & \multirow{3}{*}{$8.328 *$} \\
\hline & & Within Groups & 11.125 & 5 & 1.983 & \\
\hline & & Total & 106.557 & 9 & & \\
\hline \multirow{3}{*}{4} & \multirow{3}{*}{$\mathrm{Vy} \mathrm{cm} / \mathrm{sec}$} & Between Groups & 31.510 & 4 & 5.620 & \multirow{3}{*}{2.869} \\
\hline & & Within Groups & 12.862 & 5 & 1.911 & \\
\hline & & Total & 44.372 & 9 & & \\
\hline \multirow{3}{*}{5} & \multirow{3}{*}{$\mathrm{VR} \mathrm{cm} / \mathrm{sec}$} & Between Groups & 461.233 & 4 & 79.288 & \multirow{3}{*}{1.218} \\
\hline & & Within Groups & 372.112 & 5 & 55.341 & \\
\hline & & Total & 833.345 & 9 & & \\
\hline \multirow{3}{*}{6} & \multirow{3}{*}{ ax cm/sec2 } & Between Groups & 13.987 & 4 & 2.721 & \multirow{3}{*}{$7.421 *$} \\
\hline & & Within Groups & 17.452 & 5 & 2.736 & \\
\hline & & Total & 37.557 & 9 & & \\
\hline \multirow{3}{*}{7} & \multirow{3}{*}{ ay $\mathrm{cm} / \mathrm{sec} 2$} & Between Groups & 1963.700 & 4 & 293.342 & \multirow{3}{*}{0.836} \\
\hline & & Within Groups & 271.033 & 5 & 39.852 & \\
\hline & & Total & 2234.733 & 9 & & \\
\hline \multirow{3}{*}{8} & \multirow{3}{*}{$\mathrm{aR} \mathrm{cm} / \mathrm{sec} 2$} & Between Groups & 44.108 & 4 & 7.091 & \multirow{3}{*}{$10.521 *$} \\
\hline & & Within Groups & 3.952 & 5 & 0.521 & \\
\hline & & Total & 48.060 & 9 & & \\
\hline
\end{tabular}

\footnotetext{
** Significant on $0.01=3.55$
}

Table (12) indicates statistically significant differences for rebound ball among all types of Nano-enhanced racquets during the fourth stage (rebound effect) on all variables except for SX, SY, VY, VR and aY. This led the researcher to perform LSD test to identify these differences. 
Table (13):

LSD comparison for horizontal (X) and vertical (Y) coordinates of Distances (S) of the rebound ball from every type of Nano-enhanced tennis racquets during the third stage (rebound effect)

\begin{tabular}{|c|c|c|c|c|}
\hline $\mathrm{s}$ & Comparison & Racquet Type & $\mathrm{Sx} \quad \mathrm{Cm}$ & $\mathrm{Cm} \mathrm{Sy}$ \\
\hline \multirow{4}{*}{1} & \multirow{4}{*}{ Babolat } & 2 & 0.4400 & 0.3095 \\
\hline & & 3 & 0.2205 & 0.3130 \\
\hline & & 4 & 0.0140 & 0.4740 \\
\hline & & 5 & 0.3490 & $* 0.6095$ \\
\hline \multirow{4}{*}{2} & \multirow{4}{*}{ Wilson } & 1 & 0.4400 & 0.3095 \\
\hline & & 3 & 0.0179 & 0.0565 \\
\hline & & 4 & 0.3860 & 0.1045 \\
\hline & & 5 & 0.0510 & 0.2390 \\
\hline \multirow{4}{*}{3} & \multirow{4}{*}{ Head } & 1 & 0.2205 & 0.3130 \\
\hline & & 2 & 0.0179 & 0.0565 \\
\hline & & 4 & 0.1665 & 0.1010 \\
\hline & & 5 & 0.0885 & 0.2355 \\
\hline \multirow{4}{*}{4} & \multirow{4}{*}{ Prince } & 1 & 0.0140 & 0.4740 \\
\hline & & 2 & 0.3860 & 0.1045 \\
\hline & & 3 & 0.1665 & 0.1010 \\
\hline & & 5 & 0.2950 & 0.0745 \\
\hline \multirow{4}{*}{5} & \multirow{4}{*}{ Yonex } & 1 & 0.3490 & $* 0.6095$ \\
\hline & & 2 & 0.0510 & 0.2390 \\
\hline & & 3 & 0.0885 & 0.2355 \\
\hline & & 4 & 0.2950 & 0.0745 \\
\hline
\end{tabular}

*Significant on 0.05

Table (13) indicates no statistically significant differences statistically significant differences among the five types on among the five types on SX. In addition, there are no SY but for type one in favor of type five.

Table (14):

LSD comparison for horizontal (X) and vertical (Y) coordinates of Velocities (V) and sum velocity (R) of the rebound ball from every type of Nano-enhanced tennis racquets during the third stage (rebound effect)

\begin{tabular}{|c|c|c|c|c|c|}
\hline $\mathrm{s}$ & Comparison & Racquet Type & $\begin{array}{c}\mathrm{Vx} \\
\mathrm{cm} / \mathrm{sec}\end{array}$ & $\begin{array}{c}\mathrm{Vy} \\
\mathrm{cm} / \mathrm{sec}\end{array}$ & $\begin{array}{c}\mathrm{VR} \\
\mathrm{cm} / \mathrm{sec}\end{array}$ \\
\hline \multirow{4}{*}{1} & \multirow{4}{*}{ Babolat } & 2 & 1.2525 & 0.6805 & 8.1915 \\
\hline & & 3 & $* 4.0365$ & 0.6455 & 1.3050 \\
\hline & & 4 & $* 3.2210$ & 0.09720 & 4.2965 \\
\hline & & 5 & $* 4.8405$ & 1.2425 & 11.114 \\
\hline \multirow{4}{*}{2} & \multirow{4}{*}{ Wilson } & 1 & 1.2525 & 0.6805 & 8.1915 \\
\hline & & 3 & $* 5.489$ & 1.9260 & 6.4865 \\
\hline & & 4 & $* 4.6735$ & 0.1885 & 2.4950 \\
\hline & & 5 & *6.2930 & 2.5230 & 1.7230 \\
\hline \multirow{3}{*}{3} & \multirow{3}{*}{ Head } & 1 & $* 4.0365$ & 0.6455 & 1.305 \\
\hline & & 2 & $* 5.489$ & 1.9260 & 6.4865 \\
\hline & & 4 & 0.3155 & 1.6775 & 2.4915 \\
\hline
\end{tabular}




\begin{tabular}{|c|c|c|c|c|c|}
\hline s & Comparison & Racquet Type & $\begin{array}{c}\mathrm{Vx} \\
\mathrm{cm} / \mathrm{sec}\end{array}$ & $\begin{array}{c}\mathrm{Vy} \\
\mathrm{cm} / \mathrm{sec}\end{array}$ & $\begin{array}{c}\mathrm{VR} \\
\mathrm{cm} / \mathrm{sec}\end{array}$ \\
\hline & & 5 & 0.3040 & 0.5370 & 9.0095 \\
\hline \multirow{4}{*}{4} & \multirow{4}{*}{ Prince } & 1 & $* 3.2210$ & 0.0972 & 4.2965 \\
\hline & & 2 & $* 4.6735$ & 0.1885 & 2.4950 \\
\hline & & 3 & 0.3155 & 1.6775 & 2.4915 \\
\hline & & 5 & 1.1195 & 2.2745 & 5.6180 \\
\hline \multirow{4}{*}{5} & \multirow{4}{*}{ Yonex } & 1 & $* 4.8405$ & 1.2425 & 11.1145 \\
\hline & & 2 & *6.2930 & 2.5230 & 1.7230 \\
\hline & & 3 & 0.3040 & 0.5370 & 9.0095 \\
\hline & & 4 & 1.1195 & 2.2745 & 5.6180 \\
\hline
\end{tabular}

\section{*Significant on 0.05}

Table (14) indicates statistically significant differences between the five types and types one and two in favor of type two. Comparing types one and two, there are statistically significant differences on all variables for VX

Table (15):

LSD comparison for horizontal (X) and vertical (Y) coordinates of Accelerations (a) and sum acceleration (R) of the rebound ball from every type of Nano-enhanced tennis racquets during the third stage (rebound effect)

\begin{tabular}{|c|c|c|c|c|c|}
\hline $\mathrm{s}$ & Comparison & Racquet Type & ax cm/sec2 & ay $\mathrm{cm} / \mathrm{sec} 2$ & $\mathrm{aR} \mathrm{cm} / \mathrm{sec} 2$ \\
\hline \multirow{4}{*}{1} & \multirow{4}{*}{ Babolat } & 2 & 0.4220 & 6.1960 & 0.04200 \\
\hline & & 3 & 1.6585 & $* 23.8265$ & $* 3.8330$ \\
\hline & & 4 & 2.6865 & $* 25.371$ & $* 3.1100$ \\
\hline & & 5 & 0.2210 & $* 25.4435$ & $* 4.5315$ \\
\hline \multirow{4}{*}{2} & \multirow{4}{*}{ Wilson } & 1 & 0.4220 & 6.1960 & 0.04200 \\
\hline & & 3 & 0.4365 & $* 15.5305$ & $* 3.9260$ \\
\hline & & 4 & 1.4645 & $* 17.0750$ & $* 3.2030$ \\
\hline & & 5 & 1.0430 & $* 17.1475$ & $* 4.6245$ \\
\hline \multirow{4}{*}{3} & \multirow{4}{*}{ Head } & 1 & 1.6585 & $* 23.8265$ & $* 3.8330$ \\
\hline & & 2 & 0.4365 & $* 15.5305$ & *3.926 \\
\hline & & 4 & 0.2280 & 1.2445 & 0.0035 \\
\hline & & 5 & 2.2795 & 2.3170 & 1.0185 \\
\hline \multirow{4}{*}{4} & \multirow{4}{*}{ Prince } & 1 & 2.6865 & $* 25.371$ & $* 3.110$ \\
\hline & & 2 & 1.4645 & $* 17.0750$ & $* 3.2030$ \\
\hline & & 3 & 0.2280 & 1.2445 & 0.0035 \\
\hline & & 5 & 3.3075 & 0.6725 & 1.0215 \\
\hline \multirow{4}{*}{5} & \multirow{4}{*}{ Yonex } & 1 & 0.2210 & $* 25.4435$ & $* 4.5315$ \\
\hline & & 2 & 1.0430 & $* 17.1475$ & $* 4.6245$ \\
\hline & & 3 & 2.2795 & 2.3170 & 1.0185 \\
\hline & & 4 & 3.3075 & 0.6725 & 1.0215 \\
\hline
\end{tabular}

*Significant on 0.05

Table (15) indicates no statistically significant differences among the five types on aX. There are statistically in favor of type two. There are statistically significant differences among the five types on VY while there are no statistically significant differences for all variables on VR. 
statistically significant differences among types three, four and five and other types on aR. There are statistically significant differences between types one and two and other types on aR.

Table (16):

Values of Standard Properties for all types of Nano-enhanced tennis racquets

\begin{tabular}{|c|c|c|c|c|c|c|}
\hline S & Kind (brand) & $\begin{array}{c}\text { Weight } \\
200-400 \mathrm{~g}\end{array}$ & $\begin{array}{c}\text { String bed } \\
0-100 \mathrm{~d}\end{array}$ & $\begin{array}{c}\text { Frame Flexible } \\
0-100 \mathrm{~d}\end{array}$ & $\begin{array}{c}\text { Inertia } \\
200-400 \mathrm{~g}\end{array}$ & $\begin{array}{c}\text { Balance } \\
\mathrm{cm}\end{array}$ \\
\hline 1 & Babolat & 325 & 24 & 62 & 336 & 31.5 \\
\hline 2 & Wilson & 270 & 25 & 68 & 339 & 37.8 \\
\hline 3 & Head & 290 & 29 & 67 & 370 & 36.6 \\
\hline 4 & Prince & 256 & 23 & 63 & 385 & 34.5 \\
\hline 5 & Yonex & 310 & 28 & 60 & & 36 \\
\hline
\end{tabular}

Table (16) shows that values of standard properties of the five types of racquets are different.

\section{Discussion:}

Concerning the first question: What are the biokinematic variables resulting from using nanotechnology in manufacturing tennis racquets?

\section{A) Stage Three (post-contact):}

Table (8) indicates statistically significant differences on VX, VR, aX and aR as F values were 6.045, 14.209, 5.132 and 18.633 respectively.

These results approved the validity of methods used by the researcher through fixing the racquet on vertical right angle to the floor and the angle of ball release. This is in agreement with Husain Omar \& Iad Abdurrahman (2011) as theoretically, the horizontal composite reaches its max if body release angle is (zero) horizontally while it reaches its minimum value if body release angle is $\left(90^{\circ}\right)$ and vice versa for vertical composite. Both composites are equal if body release angle is $\left(45^{\circ}\right)$ as the sum is equally divided on horizontal and vertical directions. The researcher calibrated the release angle on $\left(45^{\circ}\right)$ so that the strength of projectile no longer affects sum velocity, horizontal acceleration or sum acceleration (15:70).

The researcher assures that although Non-enhanced racquets are manufactured in different companies, they are all of the same chemical structure with various ratios. They are also approved by ITF to be used in training and competitions.

Tables (9) (10) (11) indicate velocity increase o the horizontal axis VX for the second type (Wilson) while type one (Babolat) was higher on VR, ax and aR compared to other types.

The researcher thinks that is due to the ability of tennis robot to direct the ball to the sweet spot as this produces greater velocity on both sides of the racquet. The researcher selects attempts carefully for bio-kinematic analysis. The researcher thinks that the sweet spot is not a specific spot but merely a spot on the racquet. There are several types of sweet spots including click center, vibration nut and vibration center (horizontal). These places are not the same as they have different properties. The zero spot for both forces due to their sums is the ball hitting point on hitting center. Its place is enhanced as it becomes higher on the racquet face.

Linlin Li et al (2010) indicated that the resultant force working on the player's hand is greater if the ball hits the sweet spot in longer racquets as this increases ball velocity through increasing angular velocity of the racquet head. Angular velocity is proportionate to the distance between its point of effect and the alternative axis of the player. Therefore, faster balls and longer racquets take this advantage to improve force (13:2995).

The researcher assures that the second type (Wilson) and first type (Babolat) were the highest in VR and aR with the minimal sound of ball/racquet impact. Carbon nanotubes reveal various unique mechanical properties including rigidity, durability, strength, high thermoelectric conductivity and high profile of physical characteristics as tensile strength reaches 63 mega Pascal in addition to increased width: height ratio and decreased ball/racquet impact sound.

This is in agreement with Sherif Saleh (2008) who indicated that adding VR to ball mass that is greater than racquet mass, hand velocity and the ability of performing spins according to various racquet angles, this will make the opponent unable to return the ball $(18: 288)$.

\section{B) Fourth Stage (rebound Effect):}

Table (12) indicates statistically significant differences on $\mathrm{VX}, \mathrm{aX}$ and $\mathrm{aR}$ as $\mathrm{F}$ values were 8.328, 7.421 and 10.521 respectively. 
This effect is the result of interaction between projection velocity and types of racquets in addition to the fourth stage of analysis (rebound effect). This indicates that the effects seen on $\mathrm{X}$ axis is due to the mutual interaction of these three factors combined. This indicates that this interaction affects the value of horizontal axis $\mathrm{X}$ according to these mutual effects.

Tables (13) (14) (15) indicate an increase in final distance on the horizontal axis in favor of type two (Wilson) as it is also superior on VR and VX in addition to aY and aR compared to other types of Nano-enhanced racquets.

Tables (10-14) indicate a relationship between VR of the same type during post-contact and rebound effect stages. This is due to the ball/racquet impact. There is no statistically significant difference during rebound effect stage as rebound velocity is VX and not VR.

The researcher thinks that the superiority of type two (Wilson) is due to the use of carbon nanotubes used in its construction. This is confirmed by table (1) as this type was lighter and shorter than the first type (Babolat) which was heavier and has more area compared to other types under investigation.

Abhilasha Verma (2013) indicated that The Swiss player Roger Federer who is ranked second on the list of Association of Professional Tennis Players uses Nanoenhanced Wilson racquets as it is more stable with $22 \%$ increase in force and velocity compared to regular racquets and the carbon nanotubes are the most prominent Nano materials used in sports equipment as it improves its efficiency greatly. Nevertheless, Nano materials are very expensive and complicated in dealing with them as carbon nanotubes should be integrated to fill in the gaps and limit aerodynamics $(1: 13)$.

Concerning the second question: What are the best Nano-enhanced racquets approved by ITF?

Tables (9) (10) (11) (13) (14) (15) for both third and fourth stages indicate that type two (Wilson) came first while type one (Babolat) came second, type four (Prince) came third, type three (Head) came fourth and type five (Yonex) came fifth.

Table (16) indicated that type two (Wilson) came first in frame flexibility and light weight in addition to inertia and more balance. Type one (Babolat) came second, type four (Prince) came third, type three (Head) came fourth and type five (Yonex) came fifth.

Bio-kinematic analyses are in agreement with lab tests on that type two (Wilson) is the best type. The researcher sees hear a disproportionate relation as the decreased of tensile coefficient of frame flexibility causes an increase in strings cohesion and an increase in ball rebound velocity off the racquet.

The researcher thinks that this racquet is lighter, more flexible and more stable compared with other heavier racquets. It transfers less impact force to the player's arm compared with lighter racquets. Light racquets are faster and easier to swing. Although racquet weights are decreasing until they reached $250 \mathrm{~g}$ in some models, we cannot say that lighter racquets are the best in all cases.

As for point of balance and weight distribution, there are several options the most famous of which is the totally heavy racquet with light head as it is easy to swing and hit the ball quickly or the light racquet with concentrated weight on head so as not to sacrifice force. It is clear that all advantages cannot be gathered in one racquet but we may remember that it is easy to add additional weight to the racquet head with led strips but it is hard to make heavy racquets lighter.

Kannan \& Ramakrishnan (2012) indicated that the increase of strings tension may lead to deformities on racquet frame. This may decrease racquet balance. This assures the efficiency of type two (Wilson) due to its moderate tension of strings (17:238).

Winning in tennis depends on various interactive factors including technology that plays a major role nowadays in manufacturing sports equipment.

\section{Conclusions:}

According to bio-kinematic analysis, the researcher concludes the following:

1. Kinematic variables under investigation affect ball rebound velocity greatly

2. Values of vertical velocity $S_{Y}$, horizontal velocity $S_{X}$ and sum velocity $V_{R}$ vary according to using different types of Nano-enhanced racquets.

3. Analytical and comparative studies for Nanoenhanced racquets helped showing the differences among various types of racquets.

4. As for ranking racquets, type two (Wilson) came first in frame flexibility and light weight in addition to inertia and more balance. Type one (Babolat) came second, type four (Prince) came third, type three (Head) came fourth and type five (Yonex) came fifth. 
5. There is a disproportionate relation as the decreased of tensile coefficient of frame flexibility causes an increase in strings cohesion and an increase in ball rebound velocity off the racquet.

\section{Recommendations:}

In the light of these conclusions, the researcher recommends the following:

1- In the light of bio-kinematic velocities for each type of Nano-enhanced racquets under investigation, the researcher recommends that:

- $\quad$ Type four (Prince) and type three (Head) are used for moderate levels (less than 15 and 18 years).

- $\quad$ Type two (Wilson) and type one (Babolat) are used for high levels (less than 20 for men only)

2- Coaches should use Nano-enhanced racquets for beginners and juniors

3- Nano-enhanced racquets should be manufactured in Egypt with new sizes and shapes

4- Using these results as a base for training juniors on all age groups

5- Inventing new racquets that turn ball/racquet impact forces and vibrations into rebound energy on the racquet frame

6- ITF should hold more training courses concerning analytical studies of the properties and component of Nano-enhanced racquets to enable coaches to understand these results.

\section{References}

1- Abhilasha Verma Nanotechnology in sports equipment: The game changer, http://www.nanowerk.com /spotlight/spotid=30661.php, 2013.

2- Association of Tennis Professionals TOP100,http://www.atpworldtour.com/Rankings/ Singles.aspx ,2014.

3- akulie Basic features of the babolat rdc tuning center,Babolat RDC (Racquet Diagnostic Center) Part 1,http://www.youtube.com/ watch?v=Ys3uixhG ,2013.

4- Amal Jaber The principles of biomechanics and its applications in the field of sports, "mahy house for publication and distribution, Alexandria.2013
5- Anrush Bayge Nanotechnology in Sports, http://www.wiziq.com/course/5247, photographytips-for-beginners, 2013.

6- B .Elliott Biomechanics and tennis, journal of sports science \& Medicine, p 392-396, 2009.

7- Claire Davis, Elizabeth Swinbank Making a racket: the science of tennis, magazine for A level physics students, London University, p112-127, 2013.

8- Earl Boysen Sporting Goods with Nanotechnology, http://www.understandingnano.com/sporting_good s.html ,2012.

9- Eric Butterman Design A Racket for Engineers, https://www.asme.org/engineeringtopics/articles/design/a-racket-for-engineers ,2012

10- Eric Drexler The future of nanotechnology, Mercatus Center at George Mason University, 2013.

11-International Tennis Federation Rules on the Tennis Racket, http://officialtennisrules.com/category/rules-onthe-tennis-racket, 2014.

12-KARLA OKAL Revaluation Of Nanotechnology, master Degree, Oklahoma State University, 2011.

13- Linlin Li, Seung Han Yang, Chang-Soon Hwang, Young Kim Effects of string tension and impact location on tennis playing, Journal of Mechanical Science and Technology, Volume 23 , Issue 11,2010

14- Mark Bartlett Tennis Racket - Materials, Design, Evolution and Testing, www.azom.com/article.aspx $=1559,2013$.

15-15- Omar Hussein Mardan Iyad Abdel Biomechanics in sports movements ", Library and Archives, Baghdad, 2011.

16- P.K.Chidambaram ， R.Ramakrishanan Impact, String Tension and Vibration Analysis of Nancomposite Based Tennis Racket Frame, Scholars Journal of Engineering and Technology, pp 206-211, 2014.

17- P.Kannan, R.Ramakrishnan Development of Human Pose Models for Sports Dynamics Analysis uing Video image Processing Techniques, International Journal of Sports Science and Engineering vol.06, No.04, 2012.

18-Sherif FATHY SALEH Bio-kinematic impacts resulting from the addition of anti Vibration sport tennis rackets , Theories \& Applications, (TIAE) , Faculty of Physical Education ,Abu Qir - Alexandria University, No 65, 2008 . 
19- Rebecca Lake What Are the Materials Used to Make a Tennis Racket, http://www.livestrong.com/article/ 276131materials-used-make-tennis-racket, 2014.

20- RICHARD OSBORN Blinded by nano science, http://www.insidetennis.com/best_williams_, 2013.

21- Steve Tandlich prince Tennis Ball Machine ,2013.
22- TOTH-TASCAU Mirela, DECIANU C, RUSU Lucian Design aspects of a tennis racket , Fascicle of Management and Technological Engineering, the Oradea University, 2010.

23- Yao-dong Gu, Jian-she Li Dynamic Simulation of Tennis Racket and String, International Journal of Sports Science and Engineering, Vol. 1, 2007. 
